\title{
WHAT FOLLOWS PUTTING REASON IN ITS PLACE? "NOW VEE MAY PERHAPS TO BEGIN. YES?"
}

\author{
SANFORD LEVINSON ${ }^{\dagger}$
}

\section{INTRODUCTION}

As it happens, I read Dan Kahan and Donald Braman's extremely interesting article' while on a plane, a venue where I get an increasing percentage of my reading done these days. Air travel promotes a certain kind of intellectual serendipity, given the varying materials that people bring with them to read while crossing the country. Upon finishing their decidedly academic article, I turned to the November 4, 2002, issue of The New Yorker. By uncanny coincidence, two of the articles in that issue are centrally relevant to the Kahan and Braman article and, therefore, provide a structure for my response that the editors of the University of Pennsyluania Law Review have been kind enough to solicit.

All of these writings raise extremely important-and troublesome-questions about the role of rationality in human decision making. Lawyers especially claim a devotion to abstract reason, whether through the trope of the "reasonable" person or in the almost ritualistic invocations of the notions of "stronger" and "weaker" arguments. Beyond the legal academy, of course, the whole structure of Western thought-at least since the Enlightenment, but with linkages going back to Plato and Aristotle-has focused on the duty of intellectuals to submit their claims to reason and to swear enmity to the enemies of reason. It is, then, no small matter to challenge these notions.

After finishing Kahan and Braman, the first piece I read was a review by Nicholas Lemann of Daniel Ellsberg's new book, Secrets." Ellsberg, of course, is the person who leaked the Pentagon Papers, the Pen-

* Philla Roth, PORTNOy's Complaint 274 (1969).

t W. St. John Garwood and W. St. John Garwood, Jr., Centennial Chair in Law, University of Texas School of Law.

' Dan M. Kahan \& Donald Braman, More Statistics, Less Persuasion: A Cullural Theory of Gun-Risk Perceptions, 151 U. PA. L. REV. 1291 (2003).

${ }^{2}$ Nicholas Lemann, Paper Tiger: Daniel Ellsberg's Wa; New Yorker, Nov. 4, 2002, at 96 (reviewing DANIEL ELLSBERG, SECRETS (2002)). 
tagon's "internal" history of the origins of the Vietnam War that was compiled with the approval and cooperation of high-ranking Defense Department officials. For many, including Ellsberg, the Pentagon's own (secret) narrative of the events in question betrayed an astonishing level of mendacity on the part of our country's leaders. As the war continued even after the transition from Lyndon Johnson to Richard Nixon, Ellsberg chose to convey the highly classified documents to reporters at The New York Times, among other publications." Those newspapers famously published much of what Ellsberg gave them and then successfully defended their decisions before the Supreme Court against a vigorous attack by the executive branch. ${ }^{4}$

Not surprisingly, much of Ellsberg's memoir is devoted to detailing his motives for almost certainly violating the law." As Lemann notes, though, there are deep connections between Ellsberg's arguments in Secrets and those on display in another recent, though far more esoteric, publication-his doctoral dissertation submitted to the Harvard economics department in 1962, entitled Risk, Ambiguity and Decision."

Ellsberg was part of a generation of extremely brilliant analysts who devoted their intellectual energies to constructing more rational processes of decision making, particularly under conditions of ambiguity or incomplete information. Crucial to Ellsberg's outlook-and his ultimate decision to leak the documents-was his belief, as Lemann writes, "that bad decisions were the product of inadequate information." Thus, Ellsberg was initially confident that presidents, including John F. Kennedy and Lyndon Johnson, would necessarily have made better decisions had they only received more accurate information. This conclusion, of course, is a version of the Platonic conceit that bad action betrays a deficiency of knowledge since no rational being would choose to act in dubious ways. Rationality, from this per-

${ }^{3}$ See Ellsibler, supra note 2, at 365-75 (discussing Ellsberg's decision to deliver the Pentagon Papers to The New York Times).

"In that decision, New York Tïmes Co. v. United States, 403 U.S. 713, 719 (1971), known as The Penlagon Papers Case, the Court held that the executive branch did not meet its burden of justifying the restraint of expression. See generally DAVID

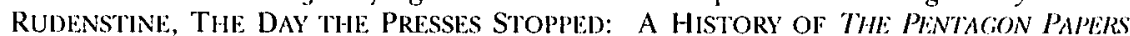
CASE (1996) (outlining the case's precipitating events and procedural history).

5 Ellsberg's prosecution was ultimately dismissed because of the Nixon administration's egregious misconduct with regard to its procurement of evidence against him. RUDENSTINE, supra note 4, at 326.

" The dissertation was later published in book form as DANIEL ELLLSBERG, RISK, AMIBICUITY AND DECISION (2001).

${ }^{7}$ Lemann, supra note 2 , at 99. 
spective, was especially to be expected of public officials, particularly with regard to such basic issues as war and peace. As Lemann writes:

For Ellsberg the shattering revelation of the Pentagon Papers was that the American Presidents who made decisions about Vietnam had actually been well informed. Nobody was lying to them about the probability of success of American engagement, and they engaged anyway. All this contradicted not only Ellsberg's own explanation for mistaken judgments but a whole way of seeing the world, in which if decision-makers can be given good information they will make rational choices.

Ellsberg's disillusionment, though, was only partial. Perhaps American leaders were less devoted to rational decision making than he thought, but he was a sufficiently good democrat to have faith in "the people." Surely his fellow Americans would turn against the war once they realized the misleading nature of many claims being made on its behalf. Knowing the truth would set them free-at least to reject an intellectually corrupt ruling elite. Thus, the leaking is best interpreted as an attempt to inform the ultimate sovereign-"We the People"-about what had been done in our name. The Pentagon Papers did not per se destroy Ellsberg's commitment to rationalistic decision theory. "[I]n leaking the Papers to the press," Lemann writes, "he was simply changing jurisdictions, trading in a faith that perfectly informed Presidents will make rational decisions for a faith that a perfectly informed public will force rational decisions on misguided Presidents." But Lemann suggests that Ellsberg's help in "providing the public with complete information didn't have the effect that Ellsberg expected."10 The war continued as if nothing had happened, with ever more carnage and destruction in its wake.

Not surprisingly, Lemann links his discussion about the Vietnam War to the current debate about Iraq, where many of us believe that the Bush administration is making decisions that are potentially even worse than those made by their predecessors forty years ago. Learned articles are published attacking the empirical premises of the Bush policy in the hope that they will affect political leaders and members of the mass public to whom the leaders are ultimately accountable. But, of course, no retreat from aggressive tactics seems to be happening; moreover, whatever else may be said about the November 2002 elections, they certainly do not manifest a revulsion by the American public about the prospect of a war that is likely to be disastrous and

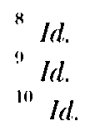


costly in every imaginable way even if, as appears likely at this time (March 21, 2003), the United States "wins" the opening battles and seizes control of Iraq.

One explanation for this response, of course, is that it is we, the opponents of the policy, who are wrong: we are the ones who are best described as obdurate and, indeed, irrational, in refusing to change our views-perhaps because we hesitate to credit the possibility that a "Texas cowboy" could be correct in his views about foreign policy. This explanation, obviously, remains within the fold of classical rational-decision theory. The polarities are simply shifted with regard to what, indeed, is the "rational" thing to do.

Lemann, however, suggests that it is the model of rational decision making embraced by Ellsberg that is fundamentally flawed. "[T]here is another explanation for the failure of accurate information to produce a single, rational outcome: the decision-makers are making value judgments about how important the goal is and how high a price they are willing to pay to achieve it." And, of course, there are almost always multiple goals, with varying prices, to further complicate any notion of "rational" decision making. "In the end," Lemann concludes,

the Vietnam War can't be reduced to a problem of miscalculated probability. It is of the utmost importance right now that we understand that the decision to go to war is ideological, not informational: the reason people disagree vehemently about war in Iraq is not that the facts on the ground or the true prospects of American military success are being kept hidden. What they disagree about is under what conditions and by what means the United States should try to affect the governance of other countries. It's not what we know but what we believe in that makes all the difference.

The other remarkable article in the November 4 issue of The New Yorker is by the late W.G. Sebald, who in A Natural History of Destruction wrote about the havoc visited upon German cities during World War II, especially the 1943 firebombing of Hamburg. ${ }^{13}$ Such raids were part of a policy initiated by the British in 1942 "to destroy the morale of the enemy civilian population and, in particular, of the industrial workers." There were, both then and now, many criticisms of this policy. Some have emphasized its arguable immorality insofar as civil-

\footnotetext{
${ }^{11}$ ld.

12 Id. (emphasis added).

1.3 W.G. Sebald, A Natural History of Destruction, NEW YORKER, Nov. 4, 2002, at 66.

I. Id. at 69 .
} 
ians essentially became the primary targets of attack; others have pointed to its inefficacy, inasmuch as morale was remarkably unaffected and, in addition, other targets might have been more valuable militarily or, as with the bombing of rail lines to Auschwitz, more productive in terms of humanitarian benefit. In any event, whatever explanations can be offered by historians for the continuance of urban bombing raids scarcely fit the models of rationalistic decision theory. Sir Arthur Harris, whose nickname was "Bomber"-and not only because he was Commander-in-Chief of Bomber Command- "inflexibly supported his strategy even when it was obviously not working." "In fact," writes Sebold, "there is much to suggest that, in Harris, a man had risen to the head of Bomber Command who ... liked destruction for its own sake.... Sir Arthur Harris's position was unassailable because of his unlimited interest in destruction."16

\section{RATIONAL DECiSION MAKING}

Kahan and Braman, like Lemann, Ellsberg, and Sebald, are essentially joined in raising absolutely fundamental questions about the ways that "we," whether as individuals or political institutions or, ultimately, as a mass political public, make our decisions. That is, to what extent does "reason" genuinely explain our behavior, or is it, as David Hume suggested, simply "the slave of the passions"? ${ }^{17}$ To paraphrase (and undoubtedly dilute) Mae West's immortal response to somebody who gasped "my goodness" upon seeing her diamonds, "Goodness had nothing to do with it," I am tempted to say that the meaning derived from all of these authors is that "reason" has little, or nothing, to do with the choices we actually make. Instead, our decisions are far better explained as the result of "values," "ideologies," or "cultural commitments" than as neutral and detached responses, based on a

15. Id. at 70 .

${ }^{16}$ Id. As a constitutional lawyer, I am reminded of Justice Powell's repeated attempts to distinguish policies that were adopted "because of," rather than "in spite of," their unfortunate consequences on racial minorities. See, e.g., McCleskey v. Kemp, 481 U.S. 279, 280 (1987) (requiring petitioners to prove that a law was enacted "because of an anticipated racially discriminatory effect"). Were Harris a southern sheriff charged with adopting policies "because of" the misery it would bring on African Americans, he would clearly be convicted, at least if Sebald's description of his psychology is correct.

${ }^{17} 2$ David hume, A Treatise of Human nature and Dialoguls Concerning NATURAl. REligion bk. II, pt. III, \$ iii (T.H. Green \& T.H. Gose eds., Longmans, Green \& Co. 1890) (1739).

${ }^{18}$ Night After Night (Paramount Pictures 1932), quoted in BARTLETT's FAMIL.IAR QUOTATIONS 736 (Justin Kaplan ed., 17th ed. 2002). 
common metric of rationality, to "data" or "evidence." Kahan and Braman's very title, More Statistics, Less Persuasion, is a self-conscious mockery of the significance of what is ordinarily taken by many people to be a sine qua non of "rational argument" (though I shall note presently that their article is internally self-refuting on this point). Regardless of whatever else persuades, they strongly assert, statistics or other empirical work does not.

Thus, the central thrust of Kahan and Braman's piece is that "cultural identity" remains the primary determinant of peoples' differing views about gun regulation." What this means, among other things, is that "there is little reason to think that recourse to empirics can shield us from the conflict generated by clashing worldviews." ive, then, could have expected Bomber Harris to change his mind upon being informed that the devastation of Germany's cities was not having the consequences some had hoped. Similarly, it would have signified naive innocence if one believed that Lyndon Johnson would decide to become the first American president to be perceived as losing a war upon being informed that the war was in fact not being won. Going from the sublime to the ridiculous, one scarcely sees "reason" as having anything to do with explaining Bill Clinton's unfathomably reckless behavior concerning Monica Lewinsky.

I will not attempt to dispute Kahan and Braman's central point about the relationship between cultural norms, including attitudes toward risks, and substantive positions relating to the issue of gun control. I do not have the professional training to challenge their statistical analyses. Perhaps more to the point is the fact that their basic arguments feel right to me. As someone who has dabbled in the gun control debate for over a decade," I am well aware of the rigidity of that debate and the remarkable rarity with which people identified with one side or the other change their minds about issues under discussion.

With respect to the intractability of the gun debate, one might be tempted to adopt Mathew Arnold's evocation of "ignorant armies

\footnotetext{
1:) See Kahan \& Braman, supra note 1, at 1318 ("The only philosophically cogent way to resolve the gun control controversy is to address explicitly, through democratic deliberations, the question of what stance the law should take toward the competing cultural visions that animate the gun control debate.").

It: $I$. at 1320 .

21 See, e.g., Sanford Levinson, The Embarrassing Second Amendment, 99 YALE L.J. 637, 639-59 (1989) (addressing the pertinence of the constitutionally privileged "right to bear arms" to today's political struggles).
} 
clash [ing] by night,"22 except that it misses the all-important point, which I believe is an important aspect of Kahan and Braman: neither the National Rifle Association (NRA) nor members of procontrol organizations can truly be described as "ignorant." Rather, as Kahan and Braman convincingly show, those groups respond to evidence quite differently in accordance to different risk preferences and overall cultural attitudes.

To someone who begins with the belief that guns are simply evil with no redeeming social value, it is irrelevant that far more children die as the consequence of choosing to go swimming than from accidental gun injuries. ${ }^{23}$ To people, on the other hand, who see the private possession of firearms as a constitutive part of American culture (and, furthermore, an important way of guarding themselves against criminal predators or, more grandly, protecting American freedom against potential tyrants) ${ }^{24}$ the costs undoubtedly attached to such possession (and no one is deluded enough to suggest that there are no costs at all) are well worth paying. Almost no one, for example, believes that we should stop building bridges or skyscrapers simply because it can be statistically predicted that $X$ individuals will give their lives in the process of erecting them. Even more surely, few are those who would support a twenty-five-mile-per-hour speed limit because that would undoubtedly save thousands of lives, though, obviously, such a policy would be "rational" for someone committed only to the value of saving lives otherwise lost in automobile accidents.

The fact that gun control, like abortion, smoking, teenage sexuality, and, for that matter, speed limits, is an aspect of America's "culture wars" makes prospects for "rational" solution quite dim, at least if one accepts the young Daniel Ellsberg's notions of "rationality." Of course, these are not uniquely American problems. One need think only of the Indian-Pakistani dispute over the fate of Kashmir, which, among all world conflicts, is probably most likely to result in the first nuclear exchange since Nagasaki in 1945. That such an exchange would be "irrational"-indeed, "lunatic"-may have all too little to tell

22 Matihew ARnOld, Dover Beach, in POems: LyRIC and Elegiac Poems 63, 64 (1923).

23. See JAMEs B. JACOBS, CAN Gun ConTrol. WORK? 5 (2002) (“[I]n 1997, only 40 children under age 5 were killed in firearms accidents. That same year, 600 children under 5 died in drowning accidents. ... Likewise, the numbers of fatal accidents involving children under 15 included 1,050 drownings . . and 220 firearms deaths.").

${ }^{24} \mathrm{I}$, of course, am not even referring to the alleged roots of a preference for guns in desires to maintain a certain notion of masculinity. 
us about the actual odds of its occurring. Such is the power of "culture" or "ideology."

And it is vital to realize that all of us are in the grips of "culture" and "ideology." Kahan and Braman most definitely do not make the jejune call for a "liberation" from "culture" or "ideology" and concomitant movement into the impersonal Elysian (and enlightened) fields of pure reason. There is no such world, and they know it. There are only the "clashing armies," and what Kahan and Braman ask is how it is that one can arrange truces-and perhaps even mutually advantageous treaties-among them once one accepts that none will be able to force its opponents into unconditional surrender by sheer force of argument. Few questions are more important or have greater implications for issues ranging far beyond gun control.

\section{What Follows The Critique of "Reason"?}

Despite Kahan and Braman's provocative (and plausible) arguments, I was reminded when I finished their article of the famous remark of Dr. Spielvogel, Portnoy's psychiatrist in Philip Roth's classic Pornoy's Complaint, ${ }^{25}$ itself an unsparing look at the actualities of our complex culture(s) and the uncertain prospects for their synthesis. The good doctor, after hearing the unending catalogue of complaints about his patient's parents, says, "So. . . Now vee may perhaps to begin. Yes?"

What is most disappointing about the otherwise praiseworthy article by Kahan and Braman is the ultimate banality of its sentimentsnot to mention a certain measure of self-contradiction-as to what message should be drawn from their analysis. Thus, they describe themselves as delivering "exhortation to academics to apply themselves to the creation of a new expressive [rather than, presumably, "empiric"] idiom, one designed to accommodate respectful cultural deliberations over gun control." "Exhortation" is, alas, all too accurate a description:

In order to civilize the gun debate, then, moderate citizens-the ones who are repulsed by cultural imperialism of all varieties-must come out from behind the cover of consequentialism and talk through their competing visions of the good life without embarrassment. They must, in the spirit of genuine democratic deliberation, appeal to one another for

\footnotetext{
2. PhILIP ROTh, PORTNOY's COMPLAINT 274 (1969).

2lit $l d$.

${ }^{27}$ Kahan \& Braman, supra note 1, at 1295.
} 
understanding and seek policies that accommodate their respective worldviews. ${ }^{28}$

Several things are worth noting about this view of politics. I begin with the self-satisfied and, presumably, self-referential paeon to "moderate citizens" who "are repulsed by cultural imperialism of all varieties." One might first ask how many readers of this journal consider themselves "immoderate citizens" who embrace "cultural imperialism," at least at the conscious level. Our culture often seems to use terms like "immoderate" as a pejorative and "moderate" (or "centrist") as a compliment. This certainly explains the common rhetorical trope of trying to suggest that there are two equally unacceptable ends of a spectrum and that one is adopting the "reasonable" via media. (One recent name for this, in American politics, is "triangulation.") A problem with any such tropes, of course, is getting agreement on what counts as the unacceptable (and presumably culturally "imperialist") extremes. I am old enough, for example, to remember when white southern "moderates" defined themselves by rejecting the "extremists on both sides," i.e., the Ku Klux Klan and the NAACP. In an even earlier era, "moderates" were those who might bestir themselves on behalf of "gradual emancipation" (say, in a half-century or so, with full compensation, of course, for the slave owners being deprived of "their property") as against the "slavocrats" on one hand and the Garrisonians devoted to "immediate emancipation" on the other. Obviously, less tendentious (and far more admirable) examples of "moderation" could be given, but the point should be obvious: what is crucial is not the label but the actual structure of alternatives and the appeal that they might have for the analyst.

Might it not be suggested, moreover, that "moderation" can itself be a form of "cultural imperialism"? Consider in this context Yeats's oft-quoted lines:

Things fall apart; the centre cannot hold;

Mere anarchy is loosed upon the world,

The blood-dimmed tide is loosed, and everywhere

The ceremony of innocence is drowned;

The best lack all conviction, while the worst

Are full of passionate intensity.

${ }^{28}$ Id. at $1321-22$.

29 William Butler Yeats, The Second Coming, in The COllected POEMS OF W.B. YEATS 203, 203 (definitive ed. 1956). 
Though critical of the "passionate intensity" of anarchists, Yeats scarcely seems to endorse "lack of conviction." Indeed, his poem is often interpreted as a call for moderates to develop their own "passionate intensity" that can be used to confront, and ultimately to defeat, the "blood-dimmed tide[s]" that are "loosed" on the world. Most of us believe that the world would be better off if at least some social movements were eliminated-by force of arms if necessary-and it is hard to see how those we (justifiably) wish to extirpate can view us as anything other than "imperialists."

Finally, is it "immoderate" to believe that "moderation in the pursuit of justice is no virtue"?" All that one can cogently say, I believe, is that "To every thing there is a season, and a time to every purpose under the heaven ....".31 Thus, while there are most certainly times for moderation, there are just as certainly times for immoderation. Public monuments are rarely built to honor those who chose "moderation" as their life's path.

Kahan and Braman's purpose is not only to offer a discussion of the debate about gun control. It is also attached to a larger agenda, which is the criticism of what they term "liberalism." Their version of "liberalism" appears to exhibit little acceptance of deep cultural cleavages-at least with regard to open cultural debate in the public square-and wishes to "cleanse public discourse of appeals to contested cultural views altogether." ${ }^{3: 3}$ They appear to apply Michel Foucault's dismissal of professionalism as "the monologue of reason" ${ }^{, 34}$ to liberalism as such, with that "monologue". ultimately consisting of appeals to empirical data that, its proponents believe, should intellectually force any honest onlooker to only one conclusion. Needless to say, there are versions of liberalism-or, more to the point, of Enlightenment philosophy-that can be reduced to such naïve notions.

30 This concept, of course, is taken from the acceptance speech by Senator Barry Goldwater at the Republican National Convention in 1964. BAKTLEIT'S FAMILIAR QuOTATIONS, supra note 18 , at 355 n.l. Justin Kaplan notes that Goldwater's comment is similar to one made by Thomas Paine, one of the instigators of the American Revolution: "Moderation in temper is always a virtue; but moderation in principle is always a vice." BaRTlețT's FAmILIAR QuOTATIONS, supra note 18, at 355 (quoting Thomas Paine, The Rights of MAN pt. II, ch. 5 (1792)).

${ }^{31}$ Ecclesiastes 3:1 (emphasis omitted).

32 Kahan \& Braman, supra note 1, at 1323.

Id. at 1322.

34 MICHEL FOUCAULT, MADNESS AND CivilizATION: A HISTORY OF INSANI'TY IN THE AGE OF REASON, at xi (Richard Howard trans., 1965) (1961). 
But, to put it mildly, there are many other versions of liberalism as well.

Perhaps it is more fair to say that many proponents of the "liberal project" share a fear of what James Madison so notably called "factions," and that liberalism is devoted to a perhaps unsuccessful effort to detail how legitimate public decisions can be made in spite of the significant sociocultural fragmentation. But this, of course, seems to be Kahan and Braman's own project. On the basis of the content, if not the rhetoric, of their article, one could easily describe them as quintessentially "liberal" in their call for deliberation based on the mutual respect of quite different worldviews. Their "conclusion presupposes that expressive debate in law can be simultaneously pertinent and tolerant." They quite explicitly endorse the notion of "democratic deliberation." Much of the ever-expanding literature on "deliberative democracy" has been written by those who are proud to identify themselves as liberals. ${ }^{38}$ Ironically enough, in a piece devoted to the importance of "playing fair" with competing worldviews, there may be a notable unfairness in reducing a rich and complex political philosophy to their own self-serving caricature.

Kahan and Braman might respond, of course, that I am being more than a bit rhetorical myself. After all, they are scarcely Pollyanaish in their vision of the world. They are well aware of "the difficulty of adapting this strategy of pluralistic expressive deliberations to the gun control issue." The best they can do is to express a very cautious optimism based on experiences in France and Germany with regard to religion and abortion and with Native Americans with regard to the disposition of tribal artifacts. ${ }^{40}$ Conceding this, I continue to believe that the article, for all of its acknowledged strengths, basically avoids any examples of how their dialogue might actually occur. What "compromise" proposals, taking account of the cultural differences that they detail, would they proffer to the contending sides? And why would they expect acceptance, especially given Eugene Volokh's dem-

35 See, e.g., THE FEderalisT NO. 10 (James Madison) (discussing factions and defining them as groups inimical to the public good).

Kahan \& Braman, supra note 1, at 1322.

${ }^{37}$ Id. at 1318.

38 For a notable example, see AMy GUTMANN \& DENNIS THOMPSON, DEMOCRACr AND DISAGREEMENT (1996).

3) Kahan \& Braman, supra note 1 , at 1323.

40 See id. at 1322 (noting "examples of communities successfully negotiating culture-infused controversies"). 
onstration in a brilliant recent article in the Harvard Law Review, that it is often altogether "rational" for groups to reject proffered "compromises," even if the proposal makes a certain amount of sense, if they cogently view acceptance as significantly increasing the likelihood that objectionable policies would later be adopted. Indeed, Volokh repeatedly turns to the gun control issue for examples.

Further difficulties suggest themselves to anyone who actually tries to imagine the dialogues and conversations that Kahan and Braman call for. Start with a basic point: how much do they genuinely wish to repudiate the use of empirical argument? They cannot cogently argue that empirical argument is per se irrelevant to the discussion of public policy, for, as I have earlier suggested, that would be to engage in self-contradiction. Their article is saturated with empirical argument, including impressive multiple regression analyses designed to tease out exactly how much culture explains views on gun control as against other variables. The purpose of their utilization of this impressive technical apparatus is obviously to get us to change our minds about how best to approach an important issue of public policy. They cannot, therefore, logically be arguing that "empirics" should be completely ignored, only that their empirics should be given pride of place over other scholars' empirics. Fair enough, but this is far different from what is suggested by their flamboyant title.

Furthermore, how much do they actually wish to repudiate any and all of the consequentialist-oriented argument they are so keen to criticize? Can one really imagine cogent arguments about guns that never refer to the potential consequences of one policy or another? Consider, for example, debates about the treatments of breast or prostate cancer. It is obvious that decisions as to, say, mastectomies or removal of the prostate are bound up with far more than the (decidedly uncertain) statistics about the actual contribution of either of these treatments to one's life expectancy. Such decisions inevitably include one's views about sexuality and other issues that could be described as "cultural." A similar point could be made about almost any aspect of contemporary medicine, including, of course, the advisability of offering persons an alternative to enduring what they view as unacceptable levels of pain. No one should believe that there is a simple "fact of the

"th Eugene Volokh, The Mechanisms of the Slippery Slope, 116 HARV. I. REV. 1026 (2003),

${ }^{12}$ See id. at 1033-38 (evaluating the routes by which gun registration may lead to stronger gun control). 
matter" that dictates whether men and women should accept any given medical treatment for serious illness.

Does this mean, however, that empirical evidence is irrelevant? Should patients simply be asked about their values and their worldviews rather than shown, for example, the latest studies that suggest that treatment $A$ does seem to reduce the cancer in $X$ percent of the cases with $Y$ side effects, as against a treatment $B$ with different outcomes? It is impossible to believe that Kahan and Braman would reject the utility of such basic aspects of "evidence-based medicine" that heavily rely on statistical argument. But If I am correct, they should be equally unwilling to reject in toto the relevance of empirical data with regard to guns. It is one thing-and a real contribution-to be reminded that such evidence isn't everything; it is distinctly anotherand a contribution to the "know nothing" strands already present in American culture-to suggest that it is nothing. Self-styled "moderates" should especially take greater care than Kahan and Braman exhibit in their article to emphasize that they are critical only of overreliance on empirical arguments.

Still, they might respond, at least some cultural arguments are inherently impervious to empirical argument, and in this they are surely correct. Consider, for example, the design of flags or the placement of public monuments. ${ }^{43}$ These are "expressive" to the core, and it is indeed often hard to figure out what sorts of empirical data might be relevant. One could look, perhaps, at public opinion polls in order to determine likely public reaction to, say, renaming any public school in New Orleans originally named after slave owners ${ }^{44}$ or placing a statue of Arthur Ashe on Richmond's Monument Avenue, the locale of monuments to Confederate heroes." A likely lesson, though, is that one would find what social scientists would label a "U-Curve," in which there would be strong partisans of each position (i.e., the status quo on the one side versus the proposed change on the other). At that point, Kahan and Braman's counsel is almost undoubtedly correct: we must devise ways for those on opposite sides of a given culture war to approach a peace table with each side receiving enough validation

4.7 See SANFord Levinson, Written in Stone: Public Monuments in Chancing, SocieTIES (1998) (cataloguing numerous public monuments and delving into their social meaning).

${ }^{44}$ See id. at 24 (noting the public debate which ensued after George Washington's name was replaced following a school board's action prohibiting the naming of schools after former slave owners).

${ }^{45}$ See id. at 115-20 (discussing a similar debate occurring over the racial and political symbolism of statues). 
to bring about an acceptable new reality. This means, almost by definition, that one will have to refrain from the pleasure of denouncing one's opponents as the scoundrels they may well seem to be.

One might wonder, though, about the prevalence of what might be termed "purely expressive" or even "predominantly expressive" political issues. It is important to be reminded that all issues have expressive dimensions, but surely, one can construct a spectrum of issues depending on mixes of what might be termed "expressive" and "empirico-consequentialist" aspects. Kahan, for example, has written notable articles on the expressive dimensions of criminal punishment; he is an important proponent of public "shaming" as a mechanism of punishment, perhaps even as an alternative to incarceration." Is there no sense in which his own prescriptions-as substitutes for our present regimes of punishment-depend for their acceptability on the empirical consequences that would attach? Would not one want to know, for example, about the recidivism rate of those who are "shamed" rather than "invisibly" incarcerated? If placing persons in stocks or forcing them to wear scarlet letters on their clothing in fact led to remarkable personal transformations and easier reintegration as productive members of the social order, would we necessarily insist on continuing to "lock them up"? I most certainly would not! Concomitantly, if research showed that "shaming sanctions" in fact seemed to reinforce the hostility of convicted criminals to ordinary society and, therefore, increased the likelihood of recidivism, might Kahan not change his mind?

\section{CONCLUSION}

Kahan and Braman provide a vital reminder of the axiom that attention to expressive dimensions of politics is a necessary condition of any cogent political strategy involving practically any complex issue, most certainly including firearms. What this means, by definition, is that an approach devoted exclusively to certain kinds of empiricoconsequentialist argument will inevitably be of only minimal aid in procuring any kind of social peace. Indeed, such an approach may even make things worse inasmuch as it is perceived to exhibit a certain kind of blindness to the controversies about worldviews that in fact structure much of the public debate. But Kahan and Braman should

4 See Dan M. Kahan, What Do Alternative Sanctions Mean?, 63 U. CHI. L. REV. 591 , 631-52 (1996) (considering the potential of shaming penalties). 
recall, as well, that expressive argument can almost never be a sufficient condition for the presence of a serious politics.

I conclude with two final quotations. Perhaps Kahan and Braman should be read as echoing John Keats's famous call for what he called "Negative Capability, that is, when man is capable of being in uncertainties, Mysteries, doubts, without any irritable reaching after fact \& reason." ${ }^{47}$ However touched we might be by this poetic insight, it is ultimately dangerous for anyone concerned to affect public policy to find "irritable" the "reaching after fact \& reason." Far better is F. Scott Fitzgerald's comment, "The test of a first-rate intelligence is the ability to hold two opposed ideas in the mind at the same time, and still retain the ability to function." "There can, of course, be no doubt as to the possession of "first-rate intelligence" by Kahan and Braman, and one should indeed take their counsel that one must at the very same time be aware of what empirical evidence can contribute and be cognizant as well of its inevitable limitations with regard to arguments that significantly turn on culture and other mysteries of the human race.

${ }^{47}$ Letter from John Keats to George and Tom Keats (Dec. 22, 1818), reprinted in JOHN KEATS, SELECTED LETTERS 40, 41-42 (Robert Gittings ed., 2002).

${ }^{48}$ F. SCOTT FITzGerald, THE CRACK-Up 69 (Edmund Wilson ed., 1964). 
* $* * * * * * *$ 